\title{
Uso dos aplicativos Sway e Adobe para a formação tecnológica no ensino superior
}

\author{
Maria Cristina Marcelino Bento \\ Centro Universitário Teresa D'Ávila (UNIFATEA), \\ Brazil \\ criscabento@gmail.com
}

\author{
Luciani Vieira Gomes Alvareli \\ Centro Universitário Teresa D'Ávila (UNIFATEA), \\ Brazil \\ luciani.alvareli@gmail.com
}

\author{
Neide Aparecida Arruda de Oliveira \\ Centro Universitário Teresa D’Ávila (UNIFATEA), \\ Brazil \\ mnoliveira9@gmail.com
}

\begin{abstract}
Resumo - Este estudo tem como objetivo mostrar o potencial dos aplicativos Sway e Adobe no auxilio a docentes do ensino superior na organização de material digital para o aluno por meio da análise da opinião de docentes do ensino superior que frequentaram encontros de formação tecnológica. $O$ estudo foi delineado por meio do ciclo da investigação-ação, ou pesquisa-ação, sobre o encontro de formação docente, de uma instituição salesiana brasileira, focado na orientação para o uso de aplicativos no preparo de material ao aluno na era digital. Participaram do encontro vinte e cinco sujeitos docentes. Observouse que os docentes que frequentaram a formação docente estavam engajados na busca pelo aprimoramento da prática pedagógica. Conclui-se que para que as tecnologias sejam utilizadas de forma efetiva é preciso verificar quais as necessidades dos participantes do processo de ensino e aprendizagem de forma a atendê-los no fortalecimento da práxis pedagógica. $O$ reconhecimento relatado pelos docentes no que concerne o aproveitamento dos discentes, após terem passado a utilizar aplicativos como recurso pedagógico, sugere pesquisa futura com os discentes a fim de identificar o quanto essa prática pode impactar no processo de ensino e aprendizagem.
\end{abstract}

Palavras chave: Adobe, Formação Docente, Sway, Tecnologias Educacionais,

Abstract - This study aims to show the potential of the Sway and Adobe applications to help higher education teachers in the organization of digital material for the student through the analysis of the opinion of higher education teachers who attended technological training meetings. The study was delineated through the actionresearch methodology about the meeting of teacher training, from a Brazilian Salesian institution, focused on the orientation for the use of software in the preparation of material for the student in the digital era. Twenty-five teachers participated in the meeting. It was observed that the teachers who attended the teacher training were engaged in the search for the improvement of the pedagogical practice. It was concluded that for technologies to be used effectively, it is necessary to verify the needs of the participants in the teaching and learning process in order to assist them in strengthening the pedagogical praxis. The recognition reported by teachers regarding the use of students, after using the software as a pedagogical resource, suggests future research with the students to identify how much this practice can impact the teaching and learning process. Training.

Key words: Adobe, Educational Technology, Sway, Teacher

\section{INTRODUCTION}

Recursos para aprendizagem escolar aumentam cada vez mais com o advento das tecnologias móveis e sem fio. A cada instante surgem novos aplicativos, cabendo ao docente escolher qual, quando, por quê, com quem e como utilizar cada aplicativo.
$\mathrm{Na}$ era digital, estamos imersos em tecnologia, e esta promove mudanças na economia, na nossa comunicação, na forma como nos relacionamos e cada vez mais no modo como aprendemos. Professores são confrontados com o enorme desafio da mudança [1] e se questionam como garantir que suas práticas pedagógicas estão contribuindo para a formação de graduados aptos para um futuro cada vez mais volátil, complexo e incerto. Devido a esse contexto, a prática pedagógica precisa ser centrada na formação do aluno, considerando o tempo e a cultura na qual este está inserido, propondo um movimento de redesenhos da sala de aula e dos recursos pedagógicos, ou seja, do como, com o quê e o para quê das metodologias ou estratégias de ensino a fim de auxiliar os alunos a desenvoverem suas competências.

Dentre as competências necessárias na sociedade do conhecimento, de acordo com documento expedido pela Conference Board of Canada [2], estão as competências digitais.

As tecnologias digitais móveis e sem fio oportunizam novas interfaces, por meio de práticas e linguagens diferenciadas, o que impulsiona o docente a ousar, experimentar, compreender mais adequadamente tais tecnologias para utilizá-las, perfazendo o uso de multiletramentos.

A era digital amplia o redesenho educacional, entretanto, exige do docente um processo de lapidação de sua formação. Entendemos por lapidação da formação tecnológica docente o processo que ajude a: pensar de forma diferente e não linear o ensino e aprendizagem; ampliar o desenvolvimento de habilidades e competências, principalmente no que diz respeito ao uso adequado das tecnologias móveis e sem fio.

O docente precisa saber gerenciar e integrar diferentes ambientes de aprendizagem; organizar o material para o aluno em diferentes formatos, compreendendo que o acesso à informação pode se dar de diferentes formas, o que traz reflexos ao perfil do professor como facilitador no desenvolvimento de todos os participantes da interação social. É preciso sentirse docente mediador/provocador de desafios para que o aluno possa compreender e agir em sua realidade.

Uma das formas de aprimorar o processo de ensino e aprendizagem na era digital é o uso das chamadas metodologias ativas que também permeiam a interação homem-computador por meio das tecnologias da informação e comunicação móvel e sem fio (TICMS).

Esta pesquisa teve como objetivo: mostrar o potencial dos aplicativos Sway e Adobe no auxílio a docentes do ensino superior na organização de material digital para o aluno por meio da análise da opinião de docentes do ensino superior que frequentaram encontros de formação. 


\section{REVISÃO BIBLIOGRÁFICA}

"O professor que não leve a sério sua formação, que não estude, que não se esforce para estar à altura de sua tarefa não tem força moral para coordenar as atividades de sua classe. (...) A incompetência profissional desqualifica a autoridade do professor."[1]. Isso nos leva a crer que o docente precisa compreender sua formação como um processo de estudos para auxiliar seus alunos, no processo de construção do conhecimento de forma eticamente compromissada.

É certo que estamos vivendo um momento em que muitos professores são imigrantes digitais, que estão compartilhando os mesmos espaços sócio-acadêmicos com os nativos digitais, seus alunos. E, nesse movimento da era digital, cabe ao docente favorecer o entrelaçamento entre os conteúdos curriculares e a experiência do aluno, não aceitando que os desafios que distanciam as gerações docente/discente dificultem essa aproximação, por serem imigrantes e nativos digitais [2].

Cabe ao docente desenvolver habilidades e competências para navegar, também, com seu aluno no ciberespaço - "o termo significa mais do que infraestrutura material da comunicação digital, mas também o universo oceânico de informações que ele abriga, assim como os seres humanos que navegam e alimentam esse universo." [3].

Para o processo de construção do conhecimento, uma prática docente reflexiva pautada em ação-reflexão-ação[1] tende a levar o docente à compreensão da necessidade do uso das tecnologias da informação e comunicação móvel e sem fio como recursos relevantes, considerando o aluno o foco do processo de ensino e aprendizagem. Esse movimento da prática serve para ajudar o docente na interpretação: qual, quando, onde e com quem utilizar cada tipo de tecnologia digital.

A curiosidade do educador [1] é outro fator que pode movêlo à prática na/da cibercultura - conjunto de técnicas, de práticas, de modos de pensamento e de valores que se desenvolvem juntamente com o crescimento do ciberespaço [2].

Os rápidos desenvolvimentos das tecnologias da informação e comunicação móvel e sem fio indicam que o docente precisa de um modelo sólido para avaliar o valor de diferentes tecnologias, novas ou existentes, e para decidir como ou quando faz sentido para ele e seus alunos as utilizarem [4].

Nesse sentido, o processo de comunicação entre docente e discente se expande para além do momento "olho no olho". É necessário que o professor continue se comunicando pessoalmente com seus discentes, no entanto, é premente a necessidade de fazê-lo também de forma digital, por meio de tecnologias móveis, mantendo sempre o equilíbrio na interação com todos e com cada aluno [5]. Com o advento da evolução das tecnologias da informação móveis e sem fio - TIMS, a educação escolar pode ocorrer simultaneamente offline e online, pela ampliação dos espaços de aprendizagem, tanto presencial quanto virtual.

Esta pesquisa considera Ambiente Virtual de Aprendizagem (AVA) as plataformas da web 2.0, redes sociais, mundos virtuais $3 \mathrm{D}$, games, realidade aumentada e ambientes pessoais de aprendizagem [6].

Acreditamos que esse sistema, composto por diversos programas, que utilizam a tecnologia de ponta com a intenção de permitir e tornar mais efetiva a rede de relacionamentos entre seus participantes, promove a disseminação de materiais, conteúdos, conhecimento, agregando pessoas e fortalecendo redes sociais [7]. Tudo isso pode facilitar a ampliação da comunicação.

O uso de AVA na educação superior está associado: à inserção das Tecnologias da Informação e Comunicação (TIC) e posterior Tecnologias da Informação e Comunicação Móveis e Sem Fio (TIMS) e ao cumprimento da Portaria $n^{\circ} 4.059$, de 2004, que regulamenta a oferta da modalidade semipresencial para os cursos de Ensino Superior em 20\% a distância [9].

A portaria supracitada foi revogada pelo Portaria n. $1.134 \mathrm{em}$ 10 de outubro de 2017. Entre as mudanças propostas destacamos que as instituições de ensino superior ao ofertarem as disciplinas na modalidade a distância deverão incluir métodos e práticas de ensino e aprendizagem que incorporem o uso integrado de tecnologias de informação e comunicação para a realização dos objetivos pedagógicos, bem como prever encontros presenciais e atividades de tutoria.

Ressaltamos que para determinados professores, a utilização de recursos a distância torna-se bastante difícil. (...) a instituição precisa ter programas de capacitação contínua, apoio de uma equipe técnico-pedagógica e organização nas formas de gerenciar as atividades a distância dos professores com maiores dificuldades [7].

A oferta de material em um AVA requer formatos diferenciados e isso exige do docente o desenvolvimento de habilidades e competências específicas para tal, o que pode modificar a relação de espaço, tempo e comunicação com os alunos. A sala de aula se amplia. Pode-se receber informação em qualquer lugar e dia da semana [7].

O impacto da revolução tecnológica, diríamos das tecnologias da informação e comunicação móveis e sem fio TIMS, sobre a produção e a socialização do conhecimento, tem feito com que as instituições de ensino superior presencial deixem de ter exclusividade nesse oficio. Ao mesmo tempo, os AVA possibilitam diversas formas de interação homemcomputador tanto presencial, quanto a distância, ampliando a sala de aula, o que impulsiona e dinamiza também o movimento da formação docente.

\section{Metodologia}

As atividades desta pesquisa aconteceram em uma instituição de ensino superior salesiana brasileira, que adota o uso de ambiente virtual de aprendizagem - AVA como um dos elementos da ampliação da sala de aula. O local de pesquisa dispõe de núcleo de educação a distância, composto por 4 profissionais, sendo dois especialistas em EAD, um designer e um estagiário. Esta equipe tem como objetivo auxiliar docentes e discentes no uso do AVA, em diferentes horários, inclusive com atendimento a distância.

Participaram desta pesquisa professores de dois cursos de licenciatura e de um curso da área da saúde, totalizando 25 sujeitos, considerando que 3 sujeitos lecionam em mais de um dos cursos citados.

A metodologia adotada foi a pesquisa-ação, que aprimora a prática pela oscilação sistemática entre agir no campo da prática e investigar a respeito dela. Planeja-se, implementa-se, descreve-se e avalia-se uma mudança para a melhora de sua prática, aprendendo mais, no correr do processo, tanto a respeito da prática quanto da própria investigação. [8]

A pesquisa-ação, um tipo de pesquisa com base empírica, foi concebida e realizada em estreita associação com uma ação e/ou com a resolução de um problema coletivo e no qual os pesquisadores e participantes representativos da situação ou do problema estiveram envolvidos de modo cooperativo/ participativo.

Para esta pesquisa, os docentes foram alertados de que na era digital precisam compreender o design do material, saber muito bem o conteúdo que lecionam e sobretudo terem a arte de saber mediar o processo de conhecimento dos alunos.

As quatro etapas da pesquisa-ação adotadas nesta pesquisa 
foram: planejar, agir, observar e refletir.

Planejou-se o desenho da formação docente mediante as necessidades solicitadas pelos sujeitos e registradas pela equipe de EAD da instituição em questão. Ao mesmo tempo, planejouse as orientações da legislação sobre uso de tecnologias da informação e comunicação, delimitando o problema de pesquisa ora descrito nesta pesquisa, bem como a forma de solução. A implementação ocorreu de duas formas, encontros online e presenciais. Os fatos ocorridos em cada momento e as narrativas dos docentes para esses momentos foram descritos e os resultados avaliados por meio de literatura especializada no tema.

A etapa agir destacou-se entre as atividades para a lapidação tecnológica dos docentes pela utilização de aplicativos para a confecção de material para uso no AVA com os alunos. Anteriormente, na maioria das vezes, os docentes somente compartilhavam com os alunos textos em formato word ou pdf e vídeos, de forma não interligada.

Mesmo conhecendo e acreditando na filosofia da disseminação de recursos educacionais abertos (REAs), como por exemplo, o banco internacional de objetos educacionais do MEC/Brasil, recursos e materiais esses que poderiam ser indicados aos docentes, como pesquisadoras, entendemos que o docente, além de saber utilizar recursos prontos, precisa saber confeccioná-los quando for possível.

Para isso, a equipe do NEAD teve o cuidado em procurar/ selecionar/testar aplicativos livres que fossem de fácil manuseio pelos docentes sem muita familiaridade no trato de muitos cliques, aberturas e fechamentos de janelas. Entre os aplicativos selecionados, ofertaram dois: Sway e Adobe.

Sway é um aplicativo (app) digital da empresa Microsoft, apresentado como um app contador de histórias, que pode ser usado no trabalho, na escola e em casa. É um app que torna rápida e fácil a criação e o compartilhamento de relatórios interativos, apresentações, histórias pessoais e muito mais. Pode ser compartilhado de forma muito simples, por meio do compartilhamento de link.

A mediação para uso do Sway foi realizada online, pelo AVA da instituição, onde todas as informações foram disponibilizadas, a partir do tutorial do aplicativo. Havia no AVA um fórum para esclarecimento de dúvidas, monitorado durante vinte e quatro horas. Além disso, os profissionais do NEAD auxiliavam os docentes na instituição sempre que solicitados, ofertando aos docentes encontros presenciais e online.

Adobe Spark é um produto da Adobe, desenvolvido para ser mais acessível aos usuários que não desenvolveram muitas habilidades de design e/ou não dominam as ferramentas mais avançadas de aplicativos para apresentação e/ou criação de imagens.

$\mathrm{O}$ app é gratuito, facilita a qualquer pessoa e de qualquer idade criar imagens, flyers, posts para redes sociais, layouts para sites e blogs, slide shows e até mesmo vídeos, com direito a som e animações simples, por meio de templates prontos.

Para acessar a ferramenta, o usuário precisa ter uma conta da Adobe, chamada de Adobe, em que é possível vincular o Adobe Spark ao Facebook ou ao Google.

Há três apps: Spark Post, para criar imagens, posts de redes sociais, flyers e etc; Spark Pages, que permite a criação de páginas e layouts para sites e blogs; e o Spark Video, para criação de vídeos, slideshows e animações simples. Para o encontro docente em estudo apresentamos todos e trabalhamos no momento com o spark page por favorecer os objetivos daquele momento.

Os professores participantes da pesquisa foram convidados para um encontro de aprendizagem para a utilização do app
Adobe sobre preparação de material para aulas.

Os encontros aconteceram em um dos laboratórios de informática, com a mediação de dois membros do NEAD em dois dias e horários diferentes, para facilitar a presença dos docentes.

Durante esses encontros, as outras duas etapas da pesquisaação puderam ser realizadas: os docentes foram observados, e as reflexões começaram a ser anotadas pelas pesquisadoras.

\section{RESULTADOS E DISCUSSÕES}

Durante o processo de desenvolvimento da pesquisa, foi observado que todos os docentes que participaram desta pesquisa utilizam o AVA institucional como forma de ampliar a sala de aula.

Estes sujeitos publicam aos alunos, no AVA, material da aula - leitura obrigatória ou complementar, organizam tarefas, avaliações, deixam recados, registros dos combinados e ofertam oficinas sobre conteúdos de suas disciplinas.

Portanto, já demonstravam uma boa noção da relevância de aproveitar os recursos oferecidos pelo AVA institucional. A ação da equipe do NEAD teve como foco a ampliação ou o reforço para o encorajamento docente na ousadia da mudança da prática pedagógica, por meio da introdução do uso dos aplicativos apresentados.

Após os encontros online para o aprendizado do aplicativo Sway, observou-se que 23 sujeitos visualizaram o ambiente. Dois deles procuraram por ajuda para aprenderem a utilizá-lo.

$\mathrm{Na}$ medida em que estes dois docentes fizeram uso do aplicativo e comentaram sobre os bons resultados, outros docentes, quatro, de outros cursos procuraram a equipe NEAD para auxiliá-los no preparo de aulas, utilizando o Sway.

Parece-nos que o encorajamento para aprender a preparar o material para o aluno nativo digital foi ganhando força na medida em que o compartilhamento de sucesso foi relatado por alguns aos outros do grupo de docentes.

Quando os professores foram convidados para participarem do encontro para conhecer o app Adobe, muitos se manifestaram. Alguns solicitaram outra data, uma vez que tinham compromisso na primeira data marcada.

Um professor disse: "eu preciso de outro dia com vocês, o prof. X preparou a aula com aquele outro, não sei o nome", referindo-se ao Sway, "e os alunos adoraram. Tem vídeo, texto, imagem. Tudo junto, também quero aprender a fazer esta mágica."

O relato desse docente nos leva a entender que há um professor em busca da inovação para a sua sala de aula, preocupado em ter o aluno motivado, interessado.

Durante o encontro, foi ofertado aos docentes o endereço do app, de modo que cada um pode criar uma conta e iniciar a utilização. Mas, antes de apresentar como navegar no aplicativo foi perguntado o que e como eles queriam o material para poder ajudar seu aluno na constatação de conceitos e/ou reflexões acerca de situações problemas.

Naquele instante, foi preciso que cada docente entendesse o valor do planejamento do conteúdo/produto educativo a ser construído. Cada docente precisa ter claro o tema a ser trabalhado, objetivo do que seria construído, para quem, como seria utilizado, quando, onde e sobretudo o que se deve esperar do uso do produto.

Esse foi um momento rico de diálogo entre os sujeitos; de uma forma lúdica três professores disseram que iriam preparar um material que pudessem utilizar com os mesmos alunos, mas de formas diferentes, pois todos precisavam do tema, mas cada um abordá-lo-ia de forma diferente. 
Dessa interação entre os docentes percebemos as categorias que fornecem o design da interdisciplinaridade: sensibilidade, intersubjetividade, integração e interação, esta considerada a efetivação da interdisciplinaridade.

Um docente comentou, enquanto descobria as formas de utilizar o app, ou na linguagem de designers, a modelagem, que compreende técnica para fazer algo - "isso vai facilitar o uso da aula invertida em meu trabalho, posso locar conteúdo de diversas formas e já mandar uma orientação para a leitura de todo o material, depois é só aproveitar a aula".

Aula invertida está entre as metodologias ativas; propõe que o aluno deixe de ser passivo, apenas ouvinte do professor. O conteúdo é fornecido ao aluno antes da aula ser apresentada, por meio de textos, exercícios, vídeo-aulas, atividades que o aluno realiza em casa antes das aulas. O docente deixa de ser expositor de conteúdo assumindo a postura de mediador (1) ou como curador [10].

Um docente disse que pretendia treinar em casa sozinho o uso do aplicativo para ver se tinha aprendido mesmo, pois iria começar a organizar suas aulas dessa forma a partir de então. Embora pudesse preparar aula a aula com o aplicativo, percebeu que o aluno poderia navegar da forma que quisesse em cada aula (material) que ele preparasse. Este mesmo sujeito chegou a afirmar que daquele modo ficaria mais fácil auxiliar a aprendizagem significativa do aluno.

O termo aprendizagem significativa foi cunhado por Ausubel (1918-2008), pesquisador norte americano. Para o pesquisador, a aprendizagem deveria se dar de forma subjetiva e a partir do conhecimento prévio do aluno sobre o objeto a ser aprendido. Esta aprendizagem se dá mediante as interligações que o aluno faz entre o que já sabe e os conhecimentos novos de forma não linear [11].

Entendemos que a percepção do docente sobre a aprendizagem significativa e a construção do material se deu a partir do comprometimento do docente em buscar por recursos e/ou formas de auxiliar o avanço do processo de aprendizagem de seus alunos.

Considerando que o docente pode preparar o material após a sondagem sobre o que os alunos sabem a respeito do tema a ser estudado, a diversidade e profundidade do conteúdo a ser estudado fica a cargo do professor para pesquisar e ofertar diferentes objetos aos alunos.

Durante a pesquisa, percebeu-se que os docentes compreenderam que o aplicativo proporciona essa oferta, bem como uma navegação não linear, possibilitando ao estudante ler/estudar o que quiser primeiro. De forma autônoma, cada um pode construir seu conhecimento, utilizando o "caminho" que mais se fizer interessante a cada um.

Um fato interessante acerca do encontro de formação foi o diálogo entre os docentes sobre suas dificuldades/superação em utilizar as ferramentas tecnológicas. Cada um tem o seu jeito de superar, seja solicitando ajuda para alguém mais novo (nativo digital), ou fazendo anotações do passo a passo de como utilizar um app, ligar e utilizar qualquer dispositivo móvel.

Um dos docentes comentou: "quando eu comecei a trazer meu notebook para conectar ao data show ou preparar as aulas em arquivo ppt, tinha que chamar o funcionário da casa para ajudar, depois os alunos começaram a me ajudar, fui fotografando informação, desenhando e/ou escrevendo, até o dia que fiz tudo sozinho e sem precisar da 'cola'. Lembro dos meus alunos perguntando e rindo se eu não precisava mais de ajuda com os cabos e abertura de janelas".

A narrativa apresentada nos leva a rever a aprendizagem multimidiática do docente. A instrução multimídia, mensagem instrucional multimídia ou apresentação instrucional multimídia envolveria, portanto, mensagens ou representações com palavras e imagens cujo objetivo fosse desenvolver o aprendizado. $\mathrm{O}$ desafio, entretanto, não se restringiria apenas integrar informações visuais e verbais na mensagem multimídia, mas envolveria também integrá-las com o conhecimento prévio dos participantes.

Os docentes que aceitaram o desafio de aprender a utilizar os aplicativos se mostraram satisfeitos e confiantes de que estavam dinamizando suas aulas e atividades, ao terminarem o planejamento da aula, enviaram o link aos coordenadores de seus cursos, como possibilita os app. em questão, para que fosse avaliado e aprovado para disponibilização aos alunos das respectivas disciplinas.

\section{CONCLUSÕES}

O uso da pesquisa-ação neste estudo possibilitou a análise do trabalho de um grupo de docentes envolvidos em formação tecnológica docente, em especial na adequação de material ao aluno universitário da era digital. Foi possível a obtenção de dados que demonstraram os níveis de utilização das tecnologias da informação e comunicação móvel e sem fio e sua relação com a satisfação pelos professores. Estes demonstraram estar modificando sua prática pedagógica, bem como as atitudes em relação ao uso da tecnologia como forma de ampliar a sala de aula. Trata-se, contudo de indícios incipientes, mas que nos aproximam de forma decisiva de uma já muito desejada mudança pedagógica.

Por meio dos dados apresentados, compreendemos que a ampliação da aprendizagem para o uso de aplicativos em educação se dá pelo comprometimento, disponibilidade para aprender, disponibilidade temporal, compreensão da mudança da prática, mudança de perfil do docente, bem como da necessidade de apoio de pessoal qualificado para a orientação e acompanhamento.

Sendo assim, podemos dizer que a formação docente, em especial a tecnológica, precisa estar conectada aos conhecimentos prévios e necessidades do docente, de forma a implantar uma relação de confiança no trabalho em grupo, uma vez que os erros e acertos e os desafios a serem superados tornem-se menores na medida em que o docente consiga perceber, agir, avaliar, refletir e reorganizar com liberdade e consciência a sua ação práticopedagógica, aproveitando ao máximo os recursos tecnológicos para o aprimoramento do processo compartilhado de construção do conhecimento.

\section{REFERENCES}

[1] Bates, Tony. Educar na era digital: design, ensino e aprendizagem. Tradução:JoãoMattaretal. SãoPaulo:ArtesanatoEducacional,2016.

[2] Conference Board of Canada, 2014. Disponível em: $<$ http://www. conferenceboard.ca/conf/default.aspx $>$ Acesso em: 07abr.2017

[3] Freire, Paulo. Pedagogia da Autonomia: saberes necessários à pratica educativa. 31. ed. São Paulo: Paz e Terra, 1996.

[4] Prensky, Marc. Aprendizagem baseada em jogos digitais. Tradução de: Eric Yamagute. São Paulo: Senac SP, 2012.

[5] Lévy, Pierre. Cibercultura. São Paulo: 34, 1999. Tradução: Carlos Irineu da Costa.

[6] Moran, J. M. Mudando a educação com metodologias ativas. In: Souza, C. A.DE e Morales, O.E. T. (org.). Convergências Midiáticas, Educação e Cidadania: aproximações jovens. Coleção Mídias Contemporâneas, v. II, Ponta Grossa: UEPG/ PROEX, 2015. Disponível em:< http://www.youblisher. $\mathrm{com} / \mathrm{p} / 1121724$-Colecao-Midias-ContemporaneasConvergencias-Midiaticas-Educacao-e-Cidadaniaaproximacoes-jovens-Volume-II/> Acesso em: 03 jan.2016. 
[7] Mattar, Tutoria e interação em educação a distância. São Paulo: Cengage Learning, 2012.

[8] Moran, José Manuel. A educação que desejamos: novos desafios e como chegar lá. $5^{a} E$ dição. São Paulo:Papirus, 2012.

[9] Tripp, David. Pesquisa-ação: uma introdução metodológica. Tradução de: Oliveira, Lólio . Educação e Pesquisa, São Paulo, v.31 , n. 3 , p. 443-4666, set/dez.2005.

[10] Bento,M.C.M.Ambientes VirtuaisdeAprendizagemInstitucionais e não Institucionais: estudo de caso com professores de uma instituição de ensino superior salesiana. 2016. 00. Tese. (Doutorado em Tecnologia da Inteligência e Design Digital) PUC.SP. 2016.

[11] Mattar, João. DESIGN EDUCACIONAL: educação a distância na prática. São Paulo: Artesanato Educacional, 2014.

[12] Moreira, Marco Antonio. O que é afinal aprendizagem significativa. (2005) Disponível em: <http://moreira. if.ufrgs.br/oqueeafinal.pdf> Acesso em: 20 jan. 2017. 